\title{
Technology spreading in healthcare: a novel era in medicine and surgery?
}

\author{
Domenico Di Nardo ${ }^{1 *}$, Chiara Eberspacher ${ }^{1}$, Giorgio Palazzini ${ }^{1}$
}

'Department of Surgical Sciences, "La Sapienza” University, Rome, Italy

\section{To Cite}

Di Nardo D, Eberspacher C, Palazzini G. Technology spreading in healthcare: a novel era in medicine and surgery? J Gastric Surg 2020; 2(2): 45-48

\section{Publication history}

Received: April 08, 2020

Accepted: April 15, 2020

Article in press: April 18, 2020

Published on line: April 18, 2020

\section{*Correspondence to}

Dr. Domenico Di Nardo Department of Surgical Sciences Policlinico Umberto I

"La Sapienza" University

Viale Regina Elena 324

00161 Roma (RM), Italy

domenicodinardo@outlook.it

Telephone: +393281599463

\section{ABSTRACT \\ Background:}

Surgery and technological innovation have begun to move at the speed of light, with innovations and discoveries such as virtual reality, robotic systems, navigation surgery, and $5 \mathrm{G}$ networks radically revolutionizing the surgical world as well as the medical world in general, bringing significant benefits for healthcare professionals and patients alike. Technology will increasingly be a crucial element in surgical and medical development. This new therapeutic approach aims to enhance human-computer interaction by putting a new "patient" figure at its center. Multiple studies will be needed to demonstrate new advanced technological systems' noninferiority to traditional patient approaches. Scientific societies, hospitals, and healthcare professionals cannot be found ill prepared for this revolution.

Keywords:

Telesurgery, 5G, 3D printing, immersive surgery, augmented reality. 


\section{Background:}

In recent years, engineers and technology companies have striven to keep pace with rapid developments in modern surgery, including of advanced devices that allow ever quicker and more precise diagnoses and provision of therapies. This article provides an analysis of the close association between technology and surgery, with a review of the evidence from current literature. Recent technological innovations include $8 \mathrm{~K}$ vision, 3D cameras, navigation surgery, image analysis using indocyanine green fluorescence (Figure 1), virtual surgical planning, 3D printing, the use of robotics systems for telesurgery, and application of 5G to surgery[1]. Surgery can thus be used to create an all-around network together with other disciplines, especially oncology, molecular biology, medicine, nutrition, engineering, and telecommunications.

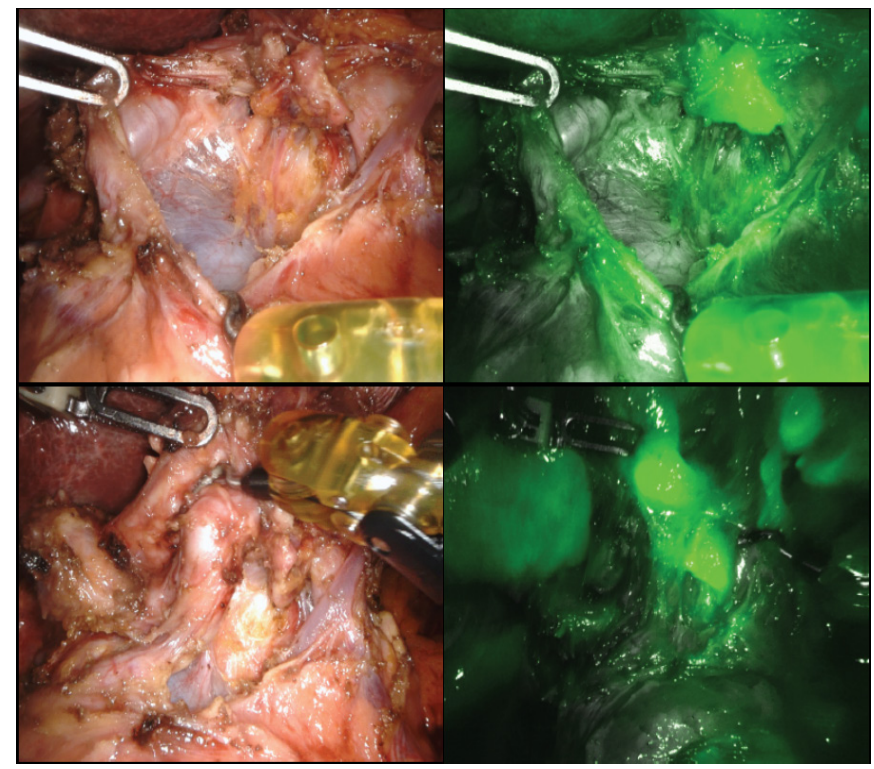

Figure 1: Fluorescence guided lymphadenectomy during total gastrectomy.

\section{Methods:}

Analysis of available published studies in the literature was performed to identify papers reporting the role of technology in medicine, robotics, 5G networks, telemedicine, and remote surgery. MEDLINE, Embase, and the Cochrane Library were searched to identify articles published through April 2020 that included reported information, details, and results concerning the medical and surgical application of advanced technological devices. Links for all search results, as well as references included in the identified articles, were reviewed to identify additional literature that was not indexed. A total of 55 potentially relevant records were identified and screened. After elimination of duplicates and exclusion of nonrelevant articles, 10 articles were read carefully and evaluated to perform a descriptive review.

\section{Results and discussion:}

\section{$3 D$ printing}

The use of 3D printing has been enjoying considerable success in the surgical field, revolutionizing medical approaches to patients both in the preoperative phase (in the study of tissues and viscera starting from axial tomography images and 2D and 3D magnetic resonance imaging) and the operating phase (using 3D-printed prostheses made of biocompatible material to repair damaged organs and tissues). 3D printing has gained increasing value in the educational field for training medical students and residents. In preoperative planning, for example, surgical simulation can help the surgeon trace the surgical steps of a procedure using a 3D-printed replica of the organ or tissue to be treated. The use of materials and specific algorithms simulates not only the patient's anatomy but even the effects of the surgical act, as described by Pugliese et al[2].

\section{IT services: websites, social networks, videos}

Thus far, IT support has been essential for general surgery development, with increasing numbers of sites, social networks, and IT tools dedicated to surgery and medicine. No scientific society, congress, or training event is possible without web support and a dedicated social platform (Facebook, Twitter, LinkedIn, and more), for such capabilities allow the rapid global spread of data. A single website can be informative and technical while containing documents (text files and videos). Both live and archived information can be made available[3]. Not only surgeons and general practitioners but also patients increasingly use the Internet and social media to search for specific information regarding diagnosis and therapy as well as information about individual specialists. Long et al.[4] reported that $65 \%$ of colorectal surgeons used the Internet from 2 to $6 \mathrm{~h}$ per week for clinical purposes, whether seeking for generic information or evidence-based literature (Figure 2). In addition, $72 \%$ of interviewed surgeons had their own website specific to their professional activity. Facebook was the preferred social media network, followed by LinkedIn and Twitter. What's more, $43 \%$ of patients searched online for information about doctors, and 75\% looked for information about symptoms or conditions.

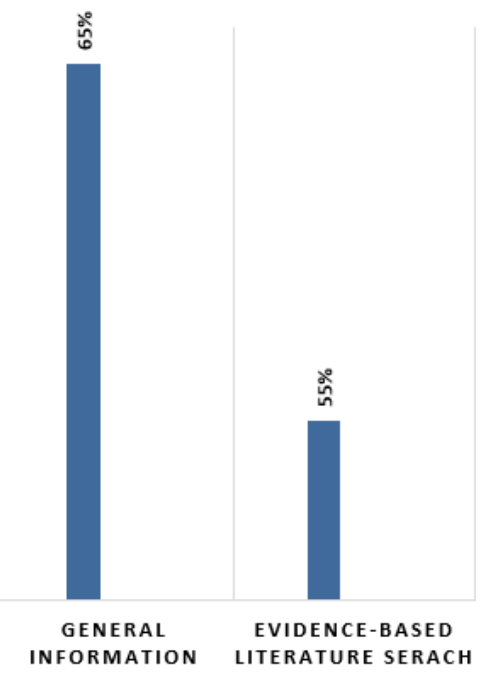

Figure 2: Use of internet among general surgeons. 


\section{G: telemedicine and telesurgery}

All the technologies thus far described have become part of everyday life, but now 5G technology is set to revolutionize the surgery-technology-communications interconnection by making huge amounts of data relating to patient diagnosis and therapy available over networks, giving an all-around view of individual patients. For example, doctors will be able to use a web platform to monitor minute chances to vital parameters, temperature, body weight, changes in lean/fat mass, metabolism, diuresis, and therapy minute by minute, day by day. Patients monitored in this way can go to the hospital only when strictly necessary, such as for surgery or urgent therapeutic reevaluation. By offering very high bandwidths at lower costs while reducing latency to a minimum, 5G overcomes the main limitation of current connections and the real obstacle to robotic telesurgery, allowing health care providers to develop a patientbased system focused on remote telemedicine diagnosis and treatments. In this way, patients can be treated and monitored worldwide using modern technologies and standardized working methods. Moreover, webbased systems can be expected to grow in accuracy and efficiency thanks to the storage of huge amounts of data for analysis by artificial intelligence, reducing bias and allowing the discovery of new diagnostic and therapeutic approaches[5]. A surgeon in one area will be able to operate on a patient in any other area of the world at any time - particularly useful for those in developing countries or war zones. Experiments have already been carried out in this field, with considerable success: on November 28, 2019, during the 30th International Congress of Digestive Surgery, held at the Auditorium del Massimo in Rome, a 5G connection was established between the congress venue and the operating room of Saint Mary's Hospital of Terni. Prof. Giorgio Palazzini, acting from Rome, used a 360-degree visor connected via a $5 \mathrm{G}$ network to carry out the first worldwide immersive surgery with remote consultation while Profs. Huang and Parisi performed a laparoscopic gastrectomy.

\section{$5 G$ and education}

Hospitals will be closely connected with universities, so that a trainee in Italy, for example, will be able to follow a surgery in China and vice versa - not merely through a simple monitor but rather through the eyes of the operating surgeon, who will wear a viewer capable of transmitting high-quality images in real time. Indeed, the world of training has already changed with the advents of smart working, interactive webinars, online lessons, virtual reality and 3D simulators (Figure 3), and

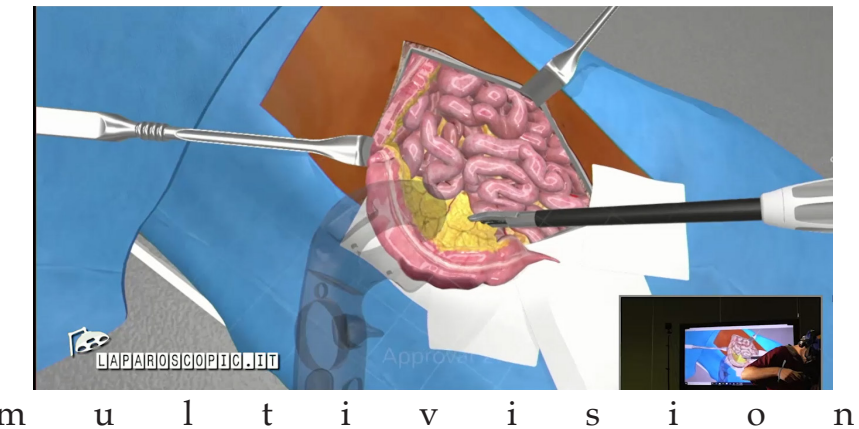

Figure 3: Virtual reality used for education of residents. streaming conferences featuring connections from around the globe (Figure 4). O'Leary et al. have demonstrated the Internet's effectiveness as a training tool for doctors in training and its ability to reduce costs in favor of an effective learning curve[6]. Sheahan et al. demonstrated how video files can be used successfully in the training and teaching of individual doctors and in the evaluation of surgical skills[7].

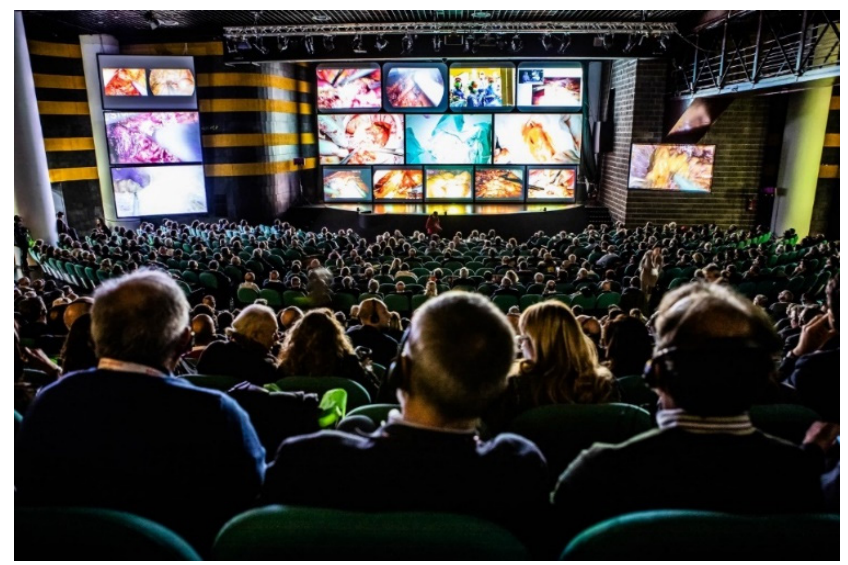

Figure 4: Live surgery during the international congress of digestive surgery (Auditorium del Massimo, Rome, Italy). Multiple connections between operating rooms from different countries and the congress venue.

\section{G: the active role of the patient}

Technology will increasingly lead patients to play a role that is active instead of passive, placing them at the center of the interactive hospital-doctor-patient process (Figure 5).

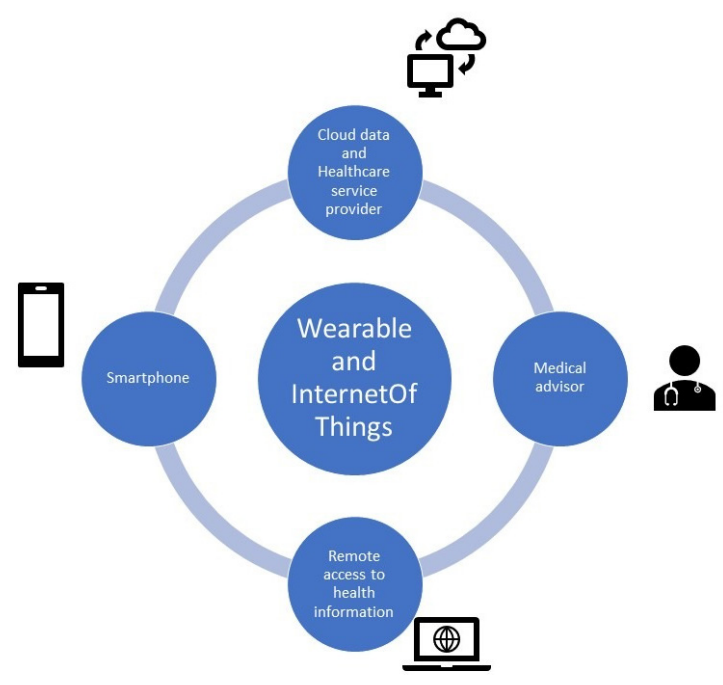

Figure 5: Integration between patient, technology and health systems.

The ever-growing market of wearable devices connected via Bluetooth (Table 1), which allows analysis and transmission of data at any time in real time, will transform the diagnostic process through an emphasis on screening and early diagnosis with the aim of reducing invasive therapies and complications of disease while increasing quality of life, reducing costs for healthcare facilities, and allowing the monitoring of chronic diseases[8]. 


\begin{tabular}{|l|l|}
\hline Sensor & Body \\
\hline Pulse & Finger \\
\hline ECG & Finger or arm \\
\hline EEG & Chest \\
\hline Body temperature & Forehead or back side of head \\
\hline Stress levels & Finger arm seam \\
\hline Sleeping & Wrist \\
\hline Walking & Wrist \\
\hline Weight and BMI & Wrist \\
\hline Kcal & Wrist \\
\hline
\end{tabular}

Table 1: biomedical sensors and measure of physiological vital signs

\section{Future perspectives}

We now face a pandemic unrivaled in the past 100 years. The face of the scientific world has completely changed, with surgery limited to emergency surgery and nondeferrable oncology surgery. As shown by Pellino and Spinelli, the ideal time for resection of colorectal cancer has been put at 3 to 6 weeks from diagnosis unlikely timing during the Sars-Cov2 epidemic. Such restrictions could reduce effectiveness of treatments over the short and long terms for oncological patients[9]. To overcome these issue, alternative strategies for patient management strategies should be devised and put in place. The biggest challenge associated with high-speed networks is that of increasing telemedicine through the use of advanced devices, thus enabling doctors to conduct patient visits remotely so as to reduce the possibility of viral spread among patients and health care providers. In the 5G era, moreover, it should become possible to reduce minimally invasive surgery's limits as they relate to contagion risk (pneumoperitoneum, nebulization of fumes from ultrasound or radio frequency instruments, anesthetic gases) through applications of robotic technology[10].

\section{Conclusion:}

The impact of these cutting-edge technologies is still unknown, as are their effects on the economy, on hospital infrastructures, on healthcare strategies and staff organization, and even on disease follow-up. However, social changes and the need to provide care are moving health systems inevitably toward greater integration of technology with medicine.

\section{Acknowledgements}

Not applicable.

\section{Contributors}

DDN, CE conceptualized and designed the study, acquired and analysed data, interpreted the study results, drafted the manuscript. GP critically revised the manuscript for important intellectual content.

\section{Funding}

No funding was received for this study.

\section{Competing interests}

No benefits in any form have been received or will be received from a commercial party related directly or indirectly to the subject of this article.

\section{Availability of data and materials}

Further information is available from the corresponding author on reasonable request.

\section{Ethics approval \\ Not applicable.}

\section{Provenance and peer review}

Not commissioned; externally peer reviewed.

\section{Open access}

This is an Open Access article distributed in accordance with the Creative Commons Attribution NonCommercial (CC BY-NC 4.0) license, which permits others to distribute, remix, adapt, build upon this work noncommercially, and license their derivative works on different terms, provided

the original work is properly cited and the use is non-commercial. See: http://creativecommons.org/ licenses/by-nc/4.0/

\section{References}

[1] Fang CH, Chen K, Zhang P. [The current situation and prospects of the application of intelligent diagnosis and treatment technology in the general surgery]. Zhonghua Wai Ke Za Zhi. 2019;57:1-5.

[2] Pugliese L, Marconi S, Negrello E, Mauri V, Peri A, Gallo V, et al. The clinical use of 3D printing in surgery. Updates Surg. 2018;70:381-8.

[3] Victer FC. Surgery and the internet. Rev Col Bras Cir. 2017;44:220-1.

[4] Long LE, Leung C, Hong JS, Wright C, Young CJ. Patterns of internet and social media use in colorectal surgery. BMC Surg. 2019;19:52.

[5] Stefano GB, Kream RM. The Micro-Hospital: 5G TelemedicineBased Care. Med Sci Monit Basic Res. 2018;24:103-4.

[6] O'Leary DP, Corrigan MA, McHugh SM, Hill AD, Redmond HP. From theater to the world wide web--a new online era for surgical education. J Surg Educ. 2012;69:483-6.

[7] Sheahan G, Reznick R, Klinger D, Flynn L, Zevin B. Comparison of Personal Video Technology for Teaching and Assessment of Surgical Skills. J Grad Med Educ. 2019;11:328-31.

[8] Haghi M, Thurow K, Stoll R. Wearable Devices in Medical Internet of Things: Scientific Research and Commercially Available Devices. Healthc Inform Res. 2017;23:4-15.

[9] Pellino G, Spinelli A. How COVID-19 Outbreak Is Impacting Colorectal Cancer Patients in Italy: A Long Shadow Beyond Infection. Dis Colon Rectum. 2020.

[10] Lisi G, Campanelli M, Spoletini D, Carlini M. The possible impact of COVID-19 on colorectal surgery in Italy. Colorectal Dis. 2020. 